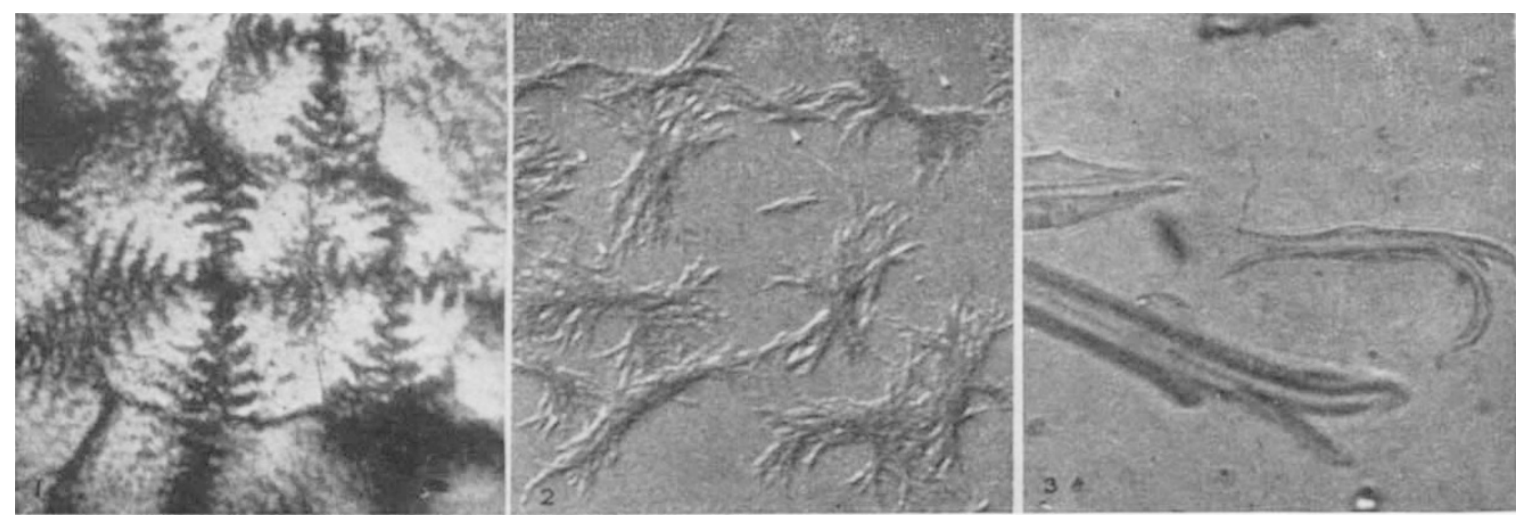

Fig. 1. Spherulites of polyethylene terephthalate formed from the melt at $220^{\circ} \mathrm{C}$. Crossed nicols. $\times 360$ Fig. 3. Drawn flbres of polyethylene terephthalate disintegrating in 0 -chlorphenol. Unpolarized light. $\times 350$

crystallization temperature) and to bigger but uncertain sizes at still higher temperatures. This agrees with the observed increase of the fibrous character of the spherulites with increasing temperature of crystallization. The fibres formed at the higher temperatures were big enough to be detached and measured under the microscope, and the measured dimensions agreed in magnitude with those which were calculated. In those cases where the fibres could be readily seen through the microscope, they proved to be flat ribbons wound in the form of a helix, which further confirms the reality of the picture proposed for the explanation of the zig-zag extinction pattern. At present nothing definite can be said about the arrangement of the molecules, but only about that of the refractive indices, within these helices. In simple polymers like polyethylene the biggest refractive index can be identified with the chain direction, but with polyethylene terephthalate conditions may be more complicated.

Electron micrographs of solvent-cast polyethylene terephthalate films show fibre bundles (Fig. 2) with fibres of about $500 \mathrm{~A}$. across, sometimes forming airscrew-like aggregations similar to those observed with the optical microscope during crystallization from the melt. The fibrils, apparently cylindrical with a well-defined periodicity along their length, proved to be in reality flat ribbons closely coiled into helices. Consequently the electron microscope showed the same morphological features in the submicroscopic region as the optical microscope showed in the microscopic region.

These facts suggest the following simplified morphological picture of crystallization. At first the molecules form fibrils which are flat and helically coiled ribbons. The relation of these new units to the molecules and to the concept of the crystallites remains to be shown. These fibrils aggregate, and eventually form spherulites, or sometimes bigger fibre bundles.

Drawn fibres of polyethylene terephthalate could be split into smaller units using suitable solvents (Fig. 3). A great variety of microfibrils of all dimensions was observed within the microscopic range. These units were always flat ribbons, often with a tendency to coil into helices. Consequently also a drawn fibre consists of secondary units which are similar to those formed spontaneously from unoriented melts and solutions. This means that drawing may not be simply a molecular process, and that the spontaneous formation of fibres is an inherent property of longchain molecules. The same conclusion has been reached in a communication by $\mathrm{Ribi}^{7}$ which appeared while this article was being prepared. Ribi has demonstrated the breakdown of various polymers into fibrils by means of supersonic radiation.

Preliminary work on synthetic polymers other than polyethylene terephthalate, such as polyethylene and polyamides, indicates that the above findings might be general and characteristic - although not always as easily observable - among all these substances. It is obvious that the existence of such complex structural units must be taken into account whenever the physical properties measured on the bulk sample are related to the molecular structure, which is particularly important for technical applications.

Finally, these phenomena may be still more general and not necessarily limited to long-chain compounds. It has been shown by Wallerant ${ }^{8}$ and also by numerous studies by Gaubert (for example, see ref. 9) that simple organic substances, minerals ànd even elements (sulphur) can. form spherulites which are built of helically-wound fibres. These authors describe numerous types of helical windings which are somewhat, though not very, different from those observed in synthetic polymers.

I am indebted to Mr. A. C. Cooper for taking the electron micrographs.

[Feb. 11 .

${ }^{1}$ Alfrey, T., "Mechanical Behaviour of High Polymers", Chapter D (Interscience, New York, 1948).

${ }^{2}$ Frey-Wyssling, A., Mühlethaler, K., and Wyckoff, R. W. G., Experientia, 4, 47 (1948).

${ }^{3}$ Bunn, C. W., and Alcock, T. C., Trans. Farad. Soc., 41, 317 (1945).

4 Bryant, W. M. D., J. Polymer Sci., 2, 547 (1947).

${ }^{5}$ Brenschede, W., Kolloid Z., 114, 35 (1949).

6 Jenckel, E., and Wilsing, H., Z. Elektrochem., 53, 4 (1949).

'Ribi, E., Nature, 168, 1082 (1951).

' Wallerant, F., Bull. Soc. franc. Miner., 30, 43 (1907).

- Gaubert, P., C.R. Acad. Sci., Paris, 162, 554 (1916).

\section{TECHNOLOGICAL EDUCATION}

$\mathrm{A}$

MONG many interesting items in his last report to the Council of the University of Birmingham, the vice-chancellor, Sir Raymond Priestley, examined the future of technological education in Britain. Britain, he suggests, has lost its lead as an industrial power, and, for remedy, no simple panacea exists. The proposal that Britain should set up a technological university along the lines of the Massachusetts Institute of Technology is, according to Sir Raymond, dangerous both to the nation and its 
existing university system. The danger lies in the diversion of a large proportion of already inadequate resources to the duplication, in an entirely different situation, of a type of education which American educationists consider to be already outdated and which they are trying to bring into line with the more conventional type of university. If a technological institute were started de novo in Britain to-morrow, it could have no decisive impact upon British industrial structure and output for a quarter of a century at least. In the meantime, the attempt at its establishment would have fatally slowed down the progress of universities and technical colleges alike.

Nor is there sure evidence that such an institution would have the decisive effect its advocates claim. The American senior technological institutes came into existence during a period of expanding economy on a newish continent in a different world. An increasing section of educated American opinion is beginning to suspect they are not so well suited to the stage the country has reached to-day.

In the United States, too, there are no institutions which skim off the cream of national youth with such skill and in such quantity in proportion to total population as Oxford and Cambridge have in the past half-century in Great Britain. This is probably the greatest single obstacle to the solution of the United Kingdom problem of diverting a reasonable proportion of the flower of the nation's educated manhood into engineering development and design-the solving of which is the main objective of the advocates of an English "M.I.T.". The pick of our youth will gravitate to Oxford and Cambridge at the undergraduate stage for a generation to come, and it is inconceivable that these particular universities will allow of the development within their boundaries of great postgraduate applied science schools. The only solution of this dilemma is the development and full exploitation of the graduate school of specialist engineering in the existing civic universities and the colleges of technology.

Sir Raymond also discussed the place of the public school in the education of the engineer. Analysis of the schoolboy entry into the departments of mechanical and civil engineering of the University of Birmingham for the period 1938-51 showed that the percentage of the grammar school entry obtaining first-class honours was nearly double the percentage of the public school entry and nearly three times that of the other secondary schools. Sir Raymond believes that the civic universities do not receive a fair sample of public school men, and that the channelling of brains and character to the public schools must aggravate the already difficult problem of producing sufficient engineers of such quality of mind and personality as will enable them to make their way on to the directorates of the great industrial concerns and to see that the best possible use is made of the genius for invention and design that the nation unquestionably possesses. In the present situation too great a proportion of the elite of our youth is likely to pass through the great humanities specialist courses - such as Greats and Modern Greats and the Cambridge Triposes-either to the Civil Service or to research in pure science. More of the best of our youth who combine strong character with highquality brain should be encouraged to learn mathematics, physics and chemistry at school, and more of them should be directed to universities where engineering is considered to be a legitimate objective for the very best men.

\section{DOCUMENTATION TECHNIQUES IN THE UNITED STATES}

THE report of the team of European experts on documentation techniques who visited the United States during November and December 1950, under the Economic Co-operation Administration Technical Assistance programme, has now been issued as an example of the contribution of the Organization for European Economic Co-operation to the improvement of European economic efficiency in the sphere of selection, reproduction and dissemination of documents*.

The three chapters of the report describe, first, the libraries and information services visited by the team, documentary reproduction techniques used in the United States, and lastly the use of punched cards and analogous techniques. While the report is largely factual, though highly condensed, each chapter includes a clear statement of the conclusions reached by the team and some recommendations; three, involving action by the Organization for European Economic Recovery, being summarized at the end. The first of these relates to the organization by competent authorities in the United States and in member countries of surveys to provide some comparative data about the degree of utilization of technical and scientific information in industrial organizations. Secondly, the report makes a representation to the United States authorities with the view of increasing the availability of 'unclassified' documents from American defence establishments to non-defence organizations in member countries. Thirdly, the import into Europe of equipment, such as special photographic equipment and special typewriters, which are only available in the United States, should also be facilitated.

For the rest of the report, the team notes the great willingness of libraries and information centres in the United States to provide a service to the technical public, as evidenced, for example, by the late hours which some libraries are open in the evening. Study of the use of Library of Congress catalogue cards is recommended as regards the possibilities both of such methods in other countries and of European co-operation in the production of the cards. The report details at some length the team's reasons for considering that micro-photography does not provide a suitable readable medium for the storage and transmission of scientific and technical information, and advocates the development of 'enlarger-scanners' for preparing enlargements of microfilms of interest. It also considers that each area should have centralized automatic facilities for enlarging microfilms so that such material as is only available on microfilms or, through currency difficulties, can be transmitted more rapidly or simply in that way, may be utilized. There appears to be considerable scope for the use of offset lithography; but progress in this field in Europe is limited by the availability of the special equipment required.

Manually sorted punched cards are more widely used in the United States than in Europe for the documentation of technical and scientific literature, but no special developments are reported. The field punched type of cards is also more widely used, both for mechanical listing operations and to facilitate

- Documentation Techniques in the U.S.A. : Selection, Reproduction, Dissemination. Beport of a Group of European Experts. Pp. 61. (Par's: Organization for European Economte Co-operation; London : H.M. Stationery Office, 1951.) 48. 